\title{
In Pursuit of the World's Best Steak - Advanced Robotics and X-ray Technology to Transform an Industry
}

\author{
Christian Ruberg \\ Meat and Livestock Australia
}

Australia strives to be the world's preferred supplier of premium red meat, but it is challenged by having a high cost structure. In response, Meat \& Livestock Australia (MLA), the processing industry, and key technology providers have spent the last 14 years developing and implementing robotic automation supported by advanced real time sensing technology such as $x$-ray imaging.

This paper outlines the investment strategy behind collaborating with the world's leading companies, and successfully integrating: meat science, industrial robotics, medical imaging, and airline baggage inspection security systems, into Australian beef and sheep meat supply chains.

These world-first systems, that were initially implemented in lamb processing, feature: robotic cutting, dual energy $x$-ray, machine vision, laser sensing, and carcase traceability for producer feedback. The beef processing sector is now set to benefit from the learnings and technical progress demonstrated in lamb processing. These innovations have moved Australia into first place for advanced red meat processing automation and have delivered in some cases an under 2-year capital payback with an up to 25\% improvement in boning room productivity.

Keywords: meat processing, robotics, innovation, industry transformation, supply chain, $x$-ray sensing

\section{EXECUTIVE SUMMARY}

The journal paper heading was "a bit cheeky" in order to catch attention. In reality, we as an industry have moved on from "In Pursuit of the World's Best Steak" due to the ever changing, and much more sophisticated, demands of our customers and consumers. However, pursuit of agility, innovation, efficiency, productivity, and profitability, across the whole value chain are still the important drivers for any organisation wishing to remain relevant and competitive.

At a high level we can be confident in the product that our industry supplies; "The high density and evolutionary bio-availability of nutrients in foods sourced from livestock underpin the future relevance of these foods in human diets" [Ferguson and Colditz 2019 ${ }^{1}$, and the evidence of growing global demand for red meat protein is that consumers everywhere also like the taste. The key, however, is maintaining global competitiveness.

Global demand for protein is growing, with a trend amongst consumers to seek out foods and food experiences that best match their very diverse values, expectations and needs, including a growing focus on their budget and value-for-money, the environment, and sustainability. Consumer insight research into 
trends indicates consumers are interested in more than just "a steak", but in the whole plate, including secondary cuts - the plate needs to offer nutritional balance, freshness, lightness, sustainability, and most importantly exciting flavours, colours, and textures.

This paper reviews the strategic approach to delivering a positive technical and commercial impact on a food-based industry with strong engineering leadership. With the scene set by a summary of current performance in global competitiveness, and with a long-term vision, with some hindsight and some foresight, the paper reviews the key factors playing a role, including the learnings from earlier success, the structural characteristics supporting innovation, the evaluation of contributors or "actors", and the evolution of important technologies. The paper concludes with some gaps, presenting researchers and interested industry observers with potential future avenues of new knowledge around industry wide innovation and achieving commercially successful outcomes. Also, technical gaps such as interpreting 3D product imaging, and meat seaming are discussed.

\section{FIGURE 1 \\ PRECISE ROBOTIC SHEEP CARCASE CUTTING GUIDED BY ADVANCED X-RAY IMAGING (SAR/JBS $\left.{ }^{2}\right)$}

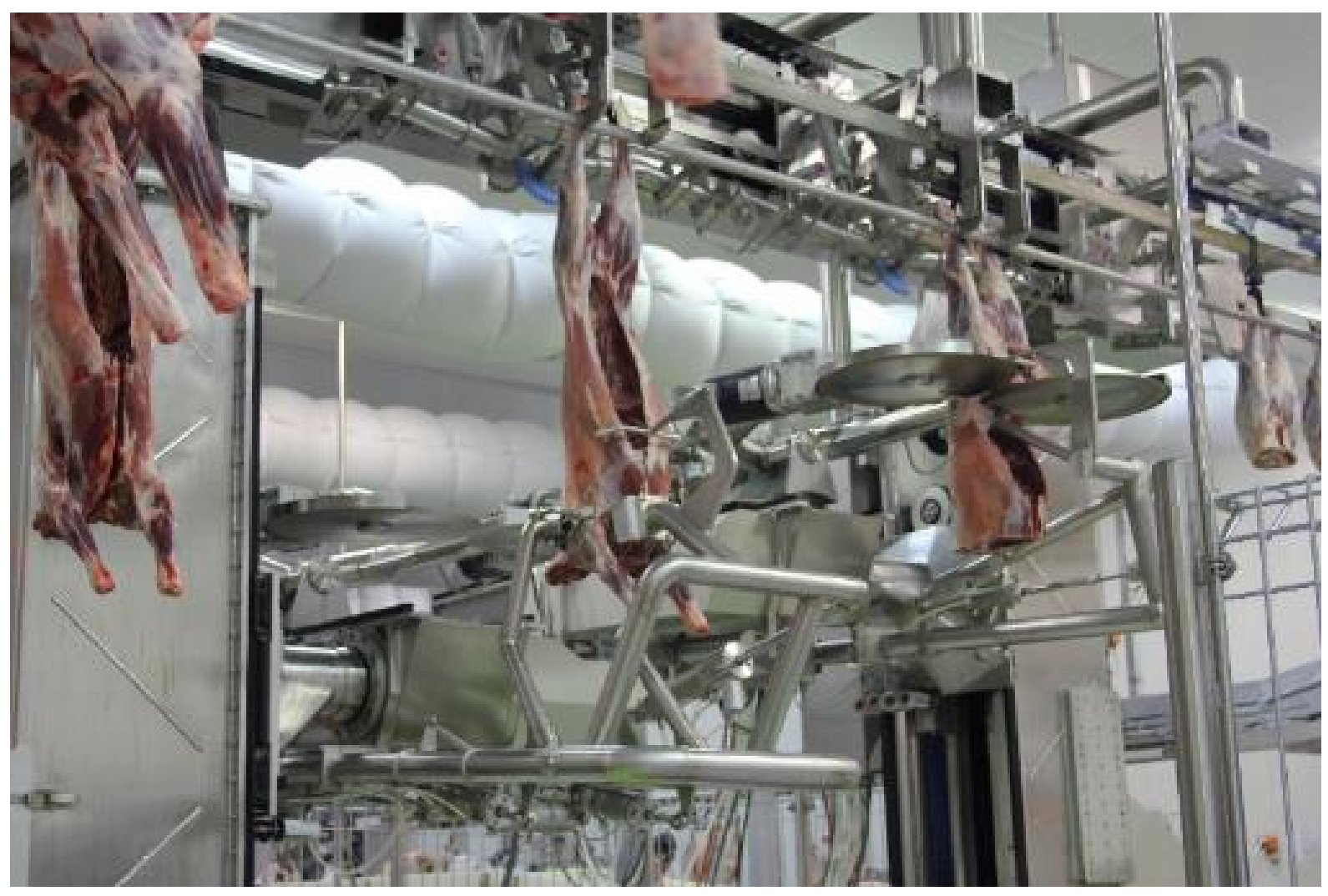

\section{OUTLINE OF STRATEGY}

\section{The Problem - Global Competitiveness}

The Australia Red Meat and Livestock sector in 2018 represents $^{3}$ : A $\$ 65 \mathrm{~B}$ turnover, A $\$ 18.4 \mathrm{~B}$ value add, A \$13.B exports, 82500 businesses, and employs 126000 direct and 312000 indirect people. Global consumption of proteins has risen around $2 \%$ per annum for the last 2 decades and is expected to continue to do so.

However, competition is coming from: non-meat alternative proteins, other meats (chicken and pork), and traditional competitors (India, Brazil, US, NZ). 
Australia is consistently one of the top beef, sheepmeat and goatmeat exporters globally ${ }^{4}$, however, competition in the international marketplace is intensifying. This is particularly apparent in beef with almost all of Australia's major beef exporter competitors forecasting production and export growth in coming years. In addition, many of these competitors are seeking to grow their share in high value markets, such as Japan or the US, placing them in more direct competition with Australia. The growing competition highlights Australia's need to be even more focused on meeting consumer needs while increasing productivity and efficiencies through the supply chain and being even more targeted in marketing to key destinations, supported by in-market intelligence and detailed consumer insights.

A number of factors combine ${ }^{5}$ to make Brazilian exports low cost and potentially responsive to changing consumer demands. When combined with a substantially lower cost of processing and production, and substantially greater vertical integration, US exports will be a key competitor to Australian red meat.

Average $\operatorname{costs}^{6}$ per head (excluding livestock purchases), which include 58\% labour related, incurred in processing beef in Australia are:

- 24 per cent higher than in the United States;

- Over twice the costs of Brazil; and,

- 75 per cent higher than in Argentina.

The current labour rate disadvantage level is likely to result in increasing pressure on the future economic sustainability of the Australian industry ${ }^{7}$. This is especially true in a global market where Australia is a price taker and where the market boundaries which previously worked in Australian red meat's favour are now moving in a direction which will expose the industry to increased competitive cost pressure.

\section{The Baseline - Australia's Performance and Rate of Productivity Improvement}

Looking at the trends over time ${ }^{8}$, Australia's red meat and livestock industry value-add increased by 61\% between 2012-13 and 2016-17, and over this period, industry value add for the production sector (beef cattle farming, sheep farming, mixed farming and feedlots) increased by $89 \%$, while industry value add for the processing sector increased by $27 \%$. Meanwhile the employment in meat processing rose from 45,300 to $62,600^{9}$, up $38 \%$.

Notwithstanding significant productivity improvements in optimising on-farm operations, and manual operations in processing over the years, the next step-change must now come from improved use of advanced technologies. 
The Vision - Automated Slaughter, Primal Cutting, De-Boning

FIGURE 2

PRECISE ROBOTICS BEEF CARCASE RIB CUTTING GUIDED BY ADVANCED X-RAY IMAGING (SAR/JBS $\left.{ }^{10}\right)$

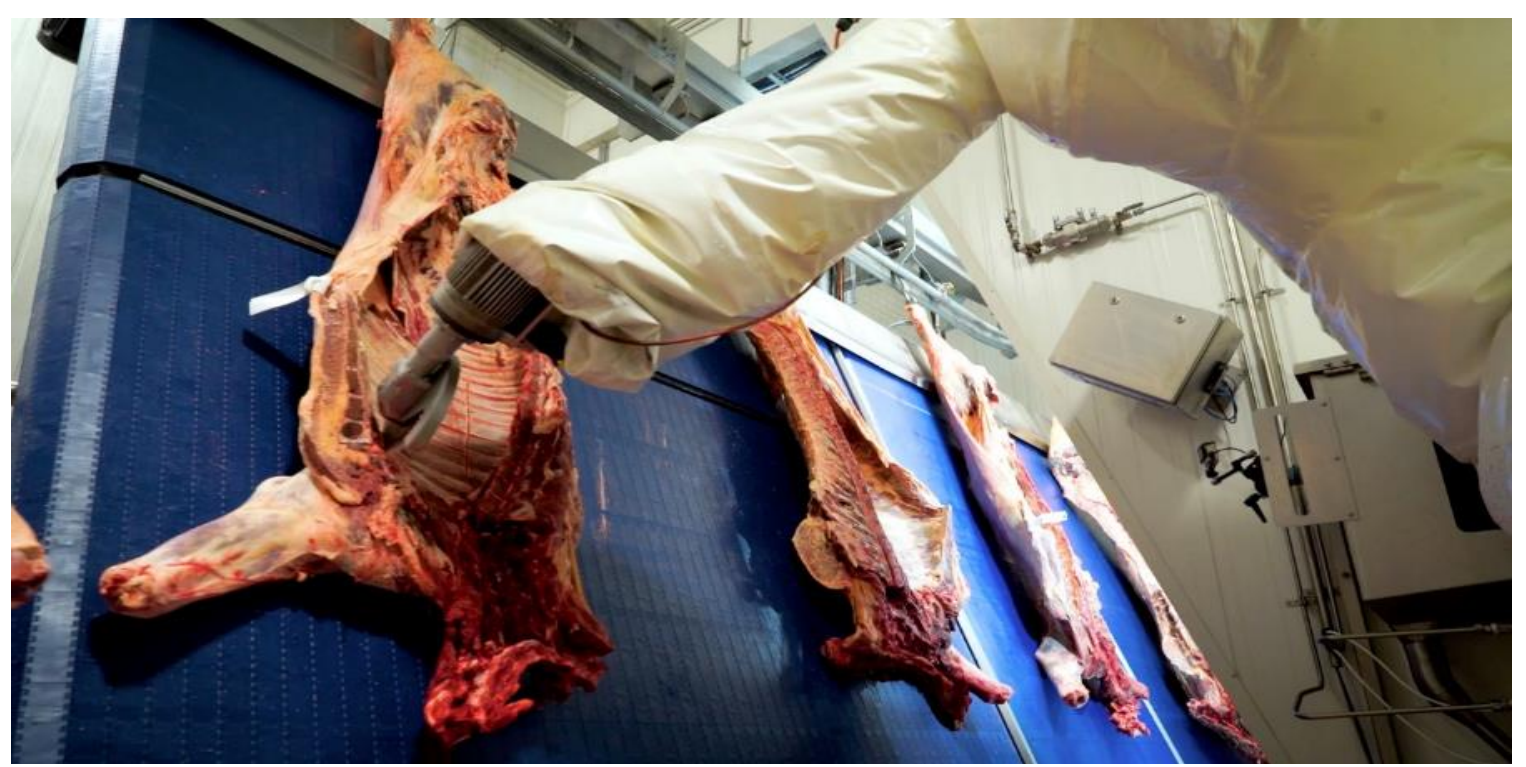

FIGURE 3

DUAL ENERGY X-RAY IMAGING TO GUIDE ROBOTIC CUTTING AUTOMATION, AND TO PROVIDE CARCASE VALUE ATTRIBUTES SUCH AS MEAT/FAT/BONE COMPOSITION AND LEAN MEAT YIELD (SAR)

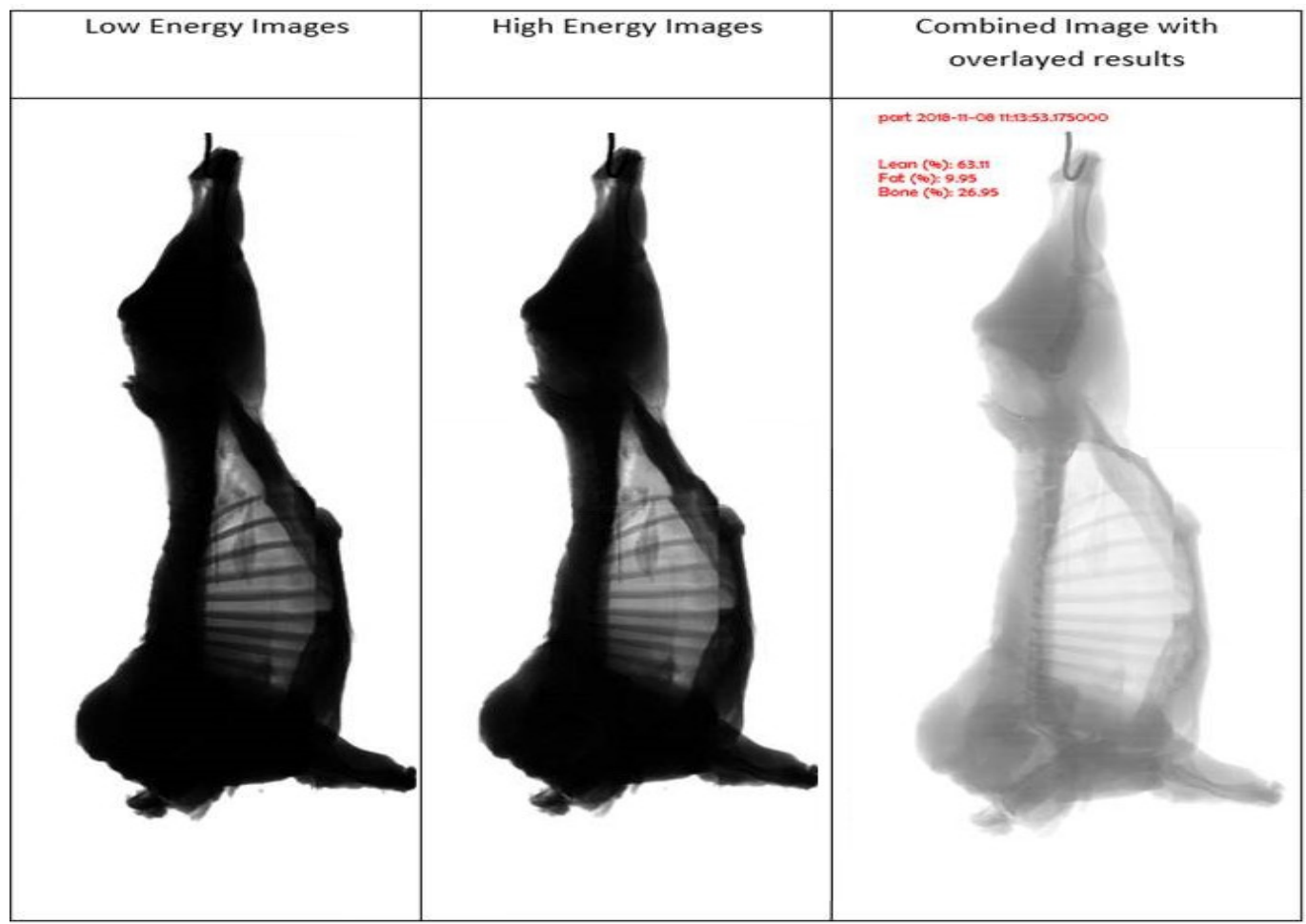




\section{The Journey - Adventuring Into the Technical Unknown}

Meat \& Livestock Australia (MLA) commenced the initiative to automate lamb processing around 15 years ago. Even with careful planning, but adventuring into the unknown, many mistakes were made. But learning from mistakes leads to progress.

The lessons learnt and recent spectacular performance successes in lamb boning automation now pave our way in beef automation and make the path forward much clearer with an anticipated far shortened development timeline. Three generations of lamb boning automation were required to finally achieve the know-how in: design effectiveness, materials usage, and production reliability.

Taking a "helicopter view", it is instructive to look back, and gain insights into what has worked, and what has not, in order to improve our future innovation journey.

\section{Historical Approaches and Learnings}

Interestingly the engineering project management philosophy has, in my view, evolved over several decades of technical innovation. In the 1980s and 1990s, the approach to technical challenge was "Crack the hardest nut and the rest will be easy". This resulted in industry challenging itself with projects which were ahead of the realistic state of the art. Examples were CSIRO's "Fututech" automated beef slaughter (circa 1990), and automated lamb hindquarter deboning (circa 2005). These initiatives, while technically impressive, failed to deliver practical cost-effective solutions. They demonstrated technical feasibility, even engineering virtuosity, but delivered no industry innovation or impact.

This approach evolved to "Let's tackle the 'low hanging fruit' first", with challenging projects taking in some cases years, almost a decade, to conclude with a successful outcome. The lamb automated middle and forequarter processing systems (circa 2006 - 2015), the automated beef carcase rib cutting (circa 2008 -2018), and the BladeStop ${ }^{\mathrm{TM}}$ bandsaw safety system (circa 2008 -2016) were examples. My complements to the tenacious and talented engineers that managed to deliver these outcomes after a long struggle, and they have ultimately made a significant positive industry impact.

The current approach, potentially borrowed from the recent IT start-up sector is, "Let's not wait until a full solution is developed, use and apply what works now, even if it is not perfect, and see where we can create value immediately". An example here may be the current development of autonomous ground and aerial vehicles. These may never be successfully delivered due to regulatory and liability factors, but many of the technical innovations are already finding their way into systems, such as; collision avoidance, lane change warning, automated parking, and journey mapping route optimisation. These are not perfect solutions but are delivering value early. So, for instance the quicker that innovations are implemented onfarm on invasive weed control, the better for our farmers - perfection not required.

\section{Learning From Innovation Systems Theory, Risk Analysis}

Effective innovation systems rely on functional and structural features [Jenson $2016^{11}$ ].

There are a number of basic factors which need to be verified before a serious attempt can be made to innovate and transform an industry. For example, structural factors include;

- innovation actor pool (ie; sufficient providers),

- technical and commercial infrastructure (ie; patent and commercialisation support),

- supporting institutions (ie; program finance, legal),

- interaction (ie; cross-functional networks),

- a market (ie; the solutions are understood by users).

While, functional factors include:

- knowledge development (ie; a body of knowledge library),

- knowledge diffusion (ie; information networks mediated with standards, and value chain participants),

- guidance of the search (ie; project management and decision support systems);

- entrepreneurial activities (ie; the ability of commercialisers to leverage their intellectual property), 
- market formation (ie; information networks that address adoption requirements, and risk),

- acceptance of change (ie; psychological factors influencing change, paradigm shifts, disruption, legitimising innovation, etc),

- resources mobilisation (ie; access to skills, finance, service and support).

Each of these factors were evaluated, gaps identified, and risk mitigation strategies actioned.

Red Meat Industry Hierarchy of Strategy

A successful investment strategy requires strategic 'buy-in' from all stakeholders. In addition to guidelines provided by industry stakeholders and the supply chain participants - ie; The Demand Side, guidance is also important from technology providers - ie; The Supply Side. The phrase 'leading from behind' is insightful here.

The industry benefits from a 5-year cycle of strategic plans, known as the Meat Industry Strategic Plan MISP. This sets the overall challenges and priorities, and attempts to align the industry, top to bottom.

Next is the corporate plan from the innovation architect. The Meat \& Livestock Australia (MLA) Strategic Plan supported by the Annual Implementation Plan (AIP), aligns the delivery of resources to the MISP, and sets the annual objectives and key performance indicators (KPIs).

The business unit activity area plan again aligns scarce resources and priorities, and sets out not only the technologies or devices being developed, but also their commercialisation and risk management issues.

Finally, leading providers also engage by submitting their technology development and commercialisation plans, updated annually.

\section{MLA Program Impact Assessment Model}

Of particular importance is the value of detailed benefit-cost analysis. This review occurs for the aggregated program area on a 5 year cycle, but also each device or initiative is assessed.

The impact assessment model integrates; the investment requirements or Inputs, the direct Outputs such as technical devices, algorithms, and reporting, but also the Outcomes or "so whats", i.e.; the more precise prediction of intramuscular fat will lead to more effective genetic selection of livestock. And finally making an assessment of "Impact", taking into account the anticipated adoption over the longer term with quantitative assessment of commercial impacts, and other intangibles, on stakeholders.

\section{FIGURE 4 \\ IMPACT ASSESSMENT MODEL ${ }^{12}$}

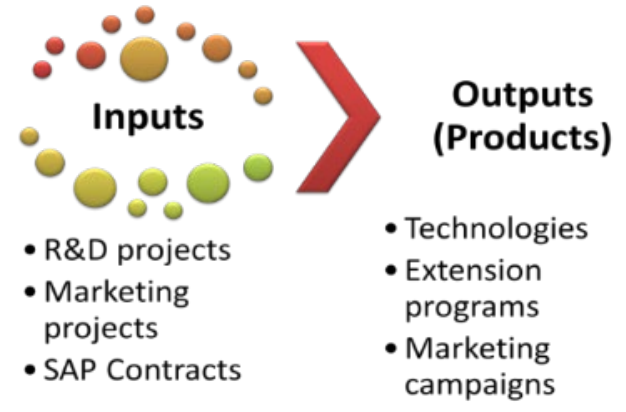

So as an example;

- Project: Automated lamb primal middle boning

- Inputs: \$40M over 15 years

- Outputs: An automatic machine to take lamb carcases and precisely break down into rack, loin, and flap, with development reporting including performance trials and benefit cost analysis.

- Outcomes: A cost effective reliable system to cleanly and precisely break down a carcase for $\$ 4 \mathrm{M}$ which adds $\$ 6 /$ carcase value at 10 carcases per minute or $1 \mathrm{M}$ per annum. The value created is 
equally shared by production and processing sector. Over time, modelling indicates value moves to livestock production and retail sectors.

- Impacts: An anticipated adoption of 10 systems over 10 years processing over $80 \%$ of smallstock with an industry NPV of $\$ 240 \mathrm{M}$, or a ROI of 5.1.

Early benefit cost analysis BCA also provides guidance to researchers and developers, by identifying the 'size of the pie', and which key areas create the most value.

Hence, adopted beef automation has an estimated $\$ 150 \mathrm{M} /$ annum benefit, as does lamb automation. Objectively measured quality and yield attributes in beef supply chains offer an estimated $\$ 60 \mathrm{M} /$ annum, while in small-stock $\$ 150 \mathrm{M} /$ annum, and $\$ 60 \mathrm{M} /$ annum applied in the lot-feeding sector.

The benefits can often be unexpected. Analysis indicates the benefits from automation do not come from labour savings (ie; only around 15\%), while carcase value yield upswing benefits represent $80 \%$ of the gains (ie; precise cutting maximising $\$ 25 / \mathrm{kg}$ product versus $\$ 3 / \mathrm{kg}$ product spanning across the cutting line), with occupational health benefits significant but smaller in comparison.

A study ${ }^{13}$ by the Danish Meat Research Institute (DMRI) ascertained that a $1 \%$ gain in gross revenue from more precise cutting is worth as much as a $12.5 \%$ reduction in wages. This further underpins the importance of automating yield critical slaughter and boning steps within beef (and lamb) processing operations.

\section{Segmenting Technology Providers}

MLA has had the opportunity of working with many technology providers over the years. Initially, there may have been a preference to work with domestic universities and local companies, both in Australia and in our neighboring market in New Zealand. Both countries benefitted from early government and industry support of basic research. Projects were typically a demonstration of technical feasibility, and were also generally technically successful.

However, they were generally commercially unsuccessful. The equipment required by the industry is technically non-trivial, and commercially substantial (ie; equipment costs between $\$ 0.25 \mathrm{M}-\$ 5 \mathrm{M}$ ). These are challenging to develop, expensive to deliver, and complex to support.

The next phase of partner selection saw a greater reliance on global sources of expertise. However, language and the "tyranny of distance" played a factor. It also became clear that the challenges in the Australian market differ quite significantly to the rest of the world. Factors such as: genetic diversity of livestock, shape and size, cycle time issues with plants operating at high throughput, and complexity of plant operation business models. Solutions that appeared effective for European pork production ultimately failed to transfer to beef and lamb processing. The nett result is that technical providers did not have the domain knowledge required to successfully offer commercial solutions.

The conclusion is that technology providers need global scale and resourcing, and innovations need to have a global market. Working exclusively with organisations over $\$ 100 \mathrm{M}$ annual turnover, with aligned strategies, seem to be the best suited to delivering commitment and impact, at the industry level.

MLA has developed some heuristics as guiding principles for processing technology/automation investment strategies:

- Sensing is the most important enabler for any task automation;

- An automated solution, to be commercially viable, must be:

- more accurate than the current human process, and

○ provide yield improvements, and or

- redeploy more than five labour units per installation

- Solution providers of fewer than 50 FTEs and or less than \$30 million turnover have no success recorded in finalising and commercialising processing technology.

\section{Segmenting Technology Buyers / Customers}

Similarly, there is value considering segmenting customers, in addition to technology providers. MLA found that clients who were operating as family businesses were often the "early adopters", and could act quickly on encouraging information. Next were a number of larger innovative organisations who could best 
be described as "fast followers", and these benefitted from not dealing with first round technical challenges and system limitations. These two groups are on the front foot, and are best able to either take advantage, or be a driver, of change and innovation financial support.

\section{Synergies Between Technical Programs}

Meat Standards Australia (MSA), representing the "voice of the consumer" was a novel and unique Australian innovation that is now gaining global recognition. Often, quality is defined by controlled manufacturing processes, Edward Deming and his total quality management TQM, aka "5 sigma" methodologies. A novel twist on this is to statistically link process factors to consumer subjective assessments. This bit of genius improves upon mere subjective assessment, for example the EUROP score, by deep understanding of consumer preferences linked to meat science, and the science of measurement or metrology.

Hence, the world's best steak is linked not to "an expert(s)", but, to juiciness, tenderness, flavour, and overall liking, precisely, by the relationship:

$$
\text { MSA score }=0.4 * \text { tenderness }+0.2 * \text { juiciness }+0.1 * \text { flavour }+0.3 * \text { overall liking }
$$

The MSA score is statistically linked to a series of key process requirements, such as the level of muscle glycogen and ultimate $\mathrm{pH}$ of the meat in the chiller, growth hormone status, Bos Indicus content, etc. The whole 'value chain', farm to processor to retailer, must contribute to the overall desired outcome - the "world's best steak".

The Australian industry can rightly be congratulated for its level of engagement and technical capability. A contributing collaboration worthy also of mention is the so called - Supply Chain Group, a team arising from the Sheep CRC ${ }^{14}$ and MLA. The supply chain group represents voices from all sectors of the value chain: livestock producers, lot-feeders, processors both beef and small-stock, retailers, universities, regional departments of agriculture, and advised by technology providers. This collaboration provides a forum for technical and commercial discussion, to ensure innovative ideas are reality checked prior to large scale investment.

\section{The $M D C-A$ Key Ingredient}

The MDC or MLA Donor Company appears to be another unique Australian idea in facilitating global innovation. The concept involves the Federal Government allocating $0.5 \%$ of red meat industry GVP $<$ Gross Value of Production $>$ in collective taxpayer funds as a pool to match both levy and commercial funds, dollar-for-dollar. The logic behind the framework is, that commercial entities are best placed to assess commercial and technical risk, and hence co-funding innovation is best placed for success. Also, the approach was anticipated to address "market failure", MLA has numerous examples of where commercial partners have indicated they would not have invested in required industry innovations without this support to manage early stage technical and commercial risk. Funds are also used to facilitate some adoption to allow innovations to cross the "valley of death" from research to commercialisation.

\section{The "Secret Sauce" - A Bold Vision}

As with perhaps all significant undertakings, success is not just the preparation and structural foundations - just ask the Ancient Greeks. In reflection, a key if not the most important ingredient for success are outstanding and insightful managers, having both deep domain knowledge and experience, but also an ability to see past conventional industry practice, to see 'outside the box'. The red meat sector workin-progress over more than 3 decades has benefitted from leadership from : industry operations participants, innovation architects from within MLA, engineering and applied science technologists, and researchers.

Insights such as "Don't spend $\$ 1 \mathrm{M}$ when $\$ 50 \mathrm{M}$ is required" are important with industry wide innovation aspirations. Sometimes audacious announcements are also required to attract industry engagement, program awareness, and emotional 'buy-in' - bold thinkers are attracted, and diffident doubters are repelled. 
A case in point was when a recent initiative was announced to roll out a key objective measurement technology across the whole industry. The announcement focused industry attention, stakeholder discussions, and played a role in the ultimate commitment to adoption.

\section{The Key Enabling Technologies to Deliver the "Perfect Steak", or a Delicious and Nutritious Red Meat Meal}

The industry has moved beyond the "perfect steak" notwithstanding its ongoing importance, but as the figure below indicates, all cuts from the carcase must be effectively utilised and optimised.

\section{FIGURE 5}

\section{THE INPUT COSTS AND OUTPUT REVENUE FROM PROCESSING.}

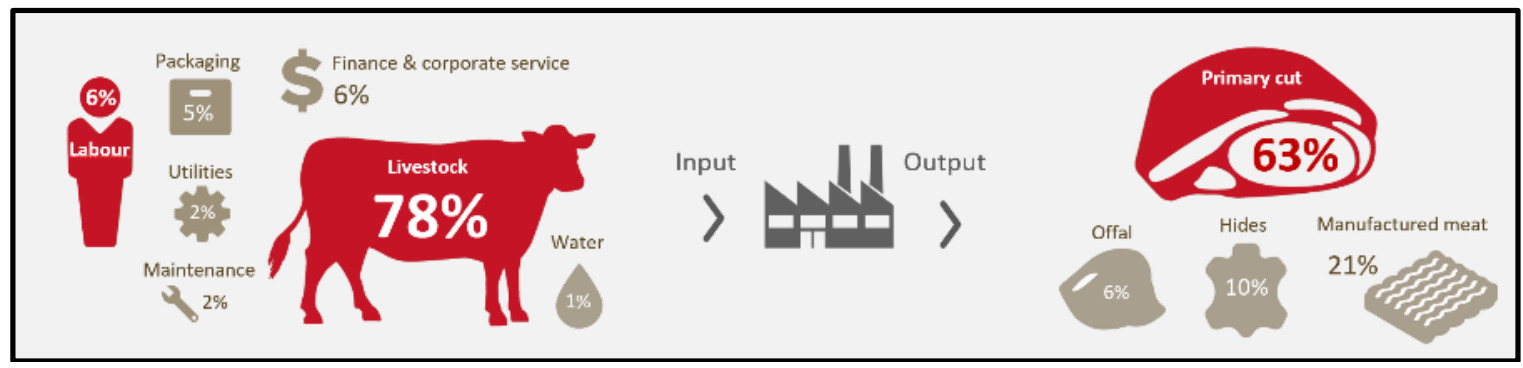

The delivery of the best possible meal outcome is dependent on a systems based foundation, however, specific technologies also play a key enabling role:

- Optimised genetics from processing feedback;

- Dual Energy X-Ray absorptiometry DEXA for saleable meat yield measurement;

- Stereo DEXA imaging for precise robotics cutting lines;

- Three dimensional 3D tomography CT via scanned x-ray, and multi-spectral imaging, for meat grading and intramuscular fat measurement;

- Measurement of ultimate $\mathbf{p H}$ to correlate for tenderness;

- Robots and fixed automation for precise and clean cutting;

- Emerging technologies to enhance human productivity: cobots, tele-robotics, exo-skeletons for improved ergonomics, augmented vision for improved gaze dependent information, and artificial intelligence for decision support.

The current state of the art in meat processing, developed by New Zealand strategic engineering partners ${ }^{15}$, and led globally by Australian processors, is advanced 3D subsurface imaging via multiple energy x-ray, integrated with machine vision analysis featuring AI algorithms, laser profiling, and industrial robotics. The outcomes are precisely cut and traceable, with 'bone-in' products, both in lamb and beef.

However, the whole area of meat from bone separation, and meat muscle seaming separation and product trimming, is currently technologically out of reach and 'next' generation, requiring substantial university level basic research. 
FIGURE 6

PRECISE ROBOTIC CUTTING REQUIRES X-RAY FOR BONE LOCATIONS, COLOUR IMAGING FOR SOME CUT TERMINATION POINTS, AND LASER DEPTH PROFILING

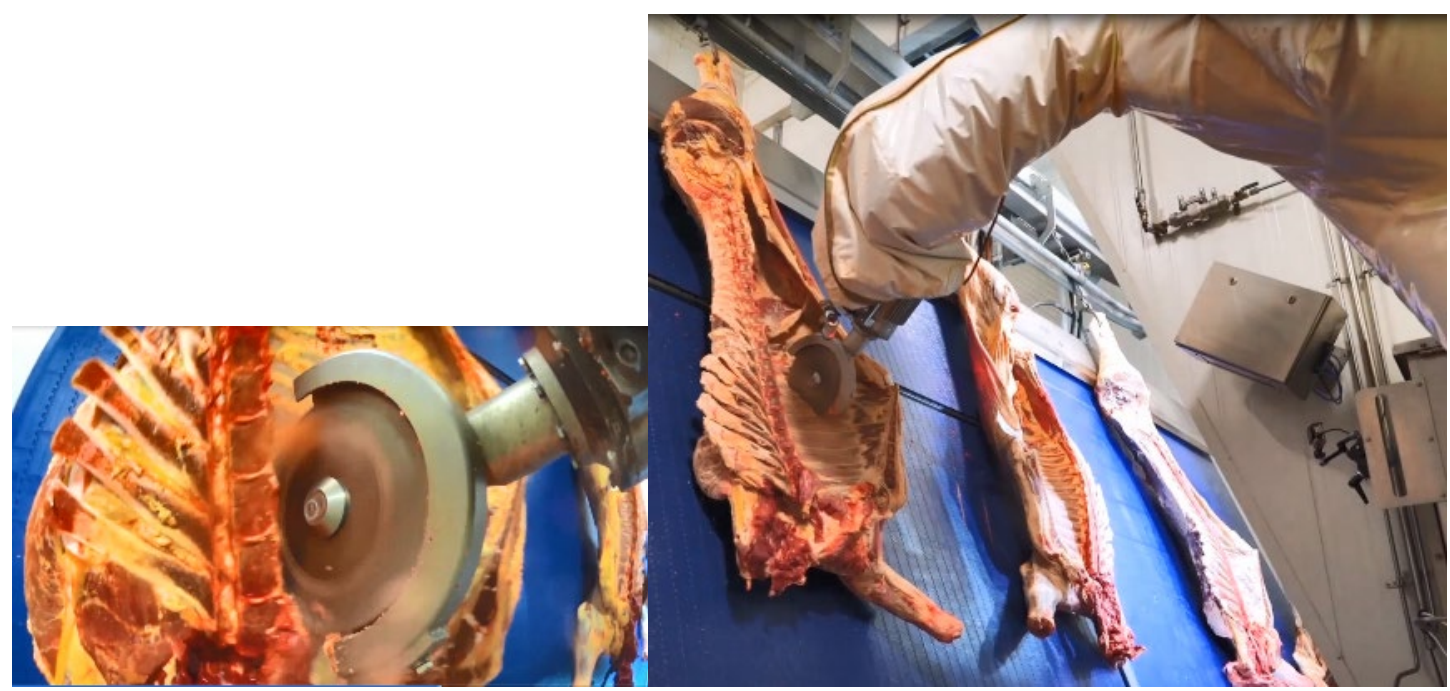

FIGURE 7

BEEF SIDE WITH AUTOMATED CUTTING LINES OVERLAYED.

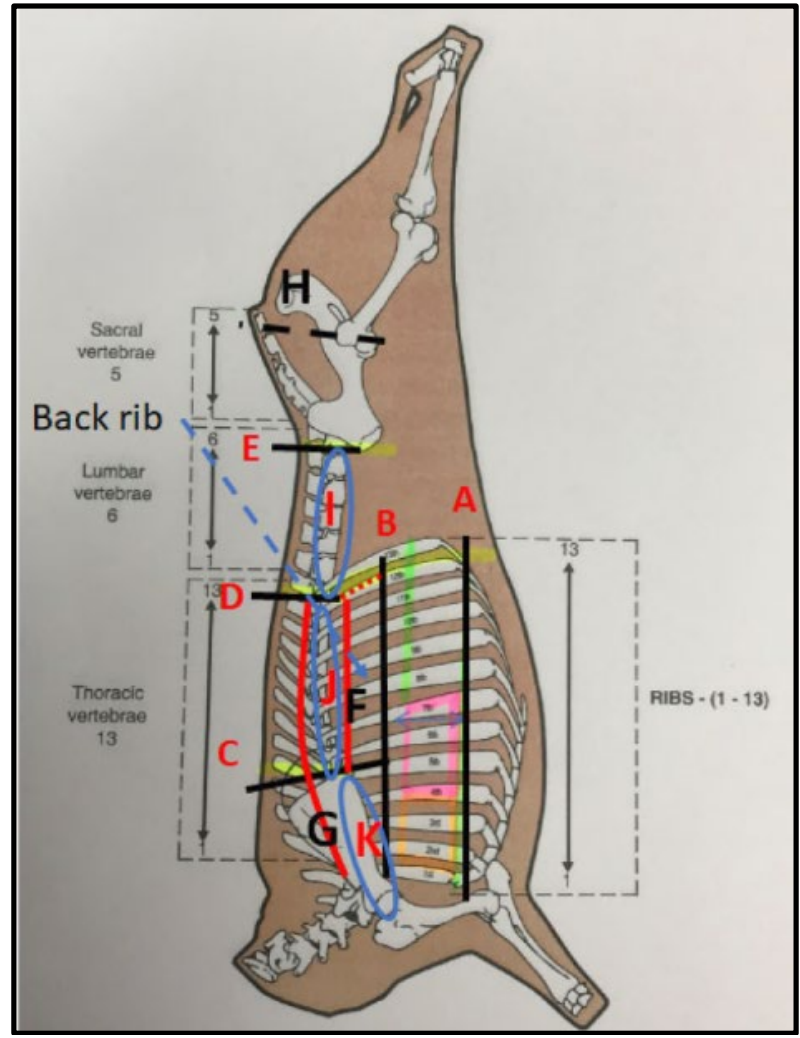

Livestock carcases are complex structures exhibiting huge size and composition variability. The technical challenges are hence at the edge of current global engineering capability, both in robotics, sensing, and algorithmic. 


\section{FIGURE 8 \\ 3D TOMOGRAPHIC RECONSTRUCTION OF BEEF PRIMAL CUT, DIGITALLY \\ SEGMENTED FROM A CARCASE SCAN, USING X-RAY TOMOGRAPHY. THE MODEL OFFERS CUTTING LINES, YIELD, GRADING, AND HEALTH INFORMATION}

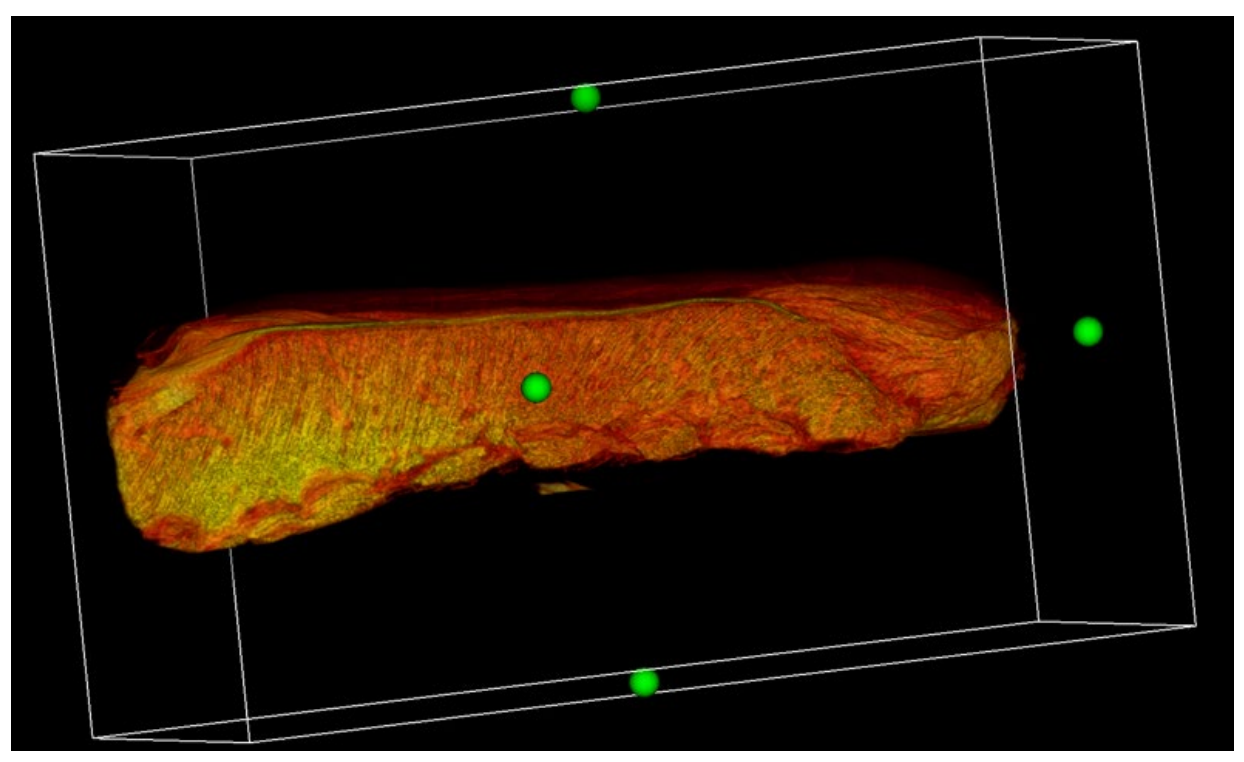

Also, as word of caution, one industry meat processing leader explained;" The challenge surrounding the provision of yield information was in ensuring that producers did not over-react. If we set price signals on meat yield to producers, then we run the risk of turning the lamb category into a 'chicken or a pork', which is essentially something lacking in flavour and bred for yield, which must be accompanied by a sauce to be eaten".

Measurement data from technology needs to be considered with a degree of insight and care. Yield measurements can drive products towards fast growing lean outcomes, while eating quality measurements can temper this with flavour, tenderness, and juiciness. This industry leader plans to give producer education a high priority, running sessions so stakeholders better understand what the data means in terms of maximising profits, improving animal health performance and 'what it is that the consumer is after' in lamb. As an extension of that, the processor also plans to introduce a supplier benchmarking analysis, comparing each producer's individual data with the broader group, in terms of weight, yield, days to market, animal health performance and other traits.

\section{When Is a Technology Investment Adoption Ready?}

Another important consideration is when a technology is ready for investment, and later for confident adoption.

Australia represents only around $2 \%$ of global $\mathrm{R} \& \mathrm{D}$ efforts, and consequently global intellectual property scanning is very important. Often transformational innovations will come from other industries, so the technology development program has sourced: augmented vision from the computer gaming sector, advanced imaging from the airline baggage inspection sector, measurement technology from veterinary and human health sectors, and robotics from the automotive sector.

All technology development programs require a pipeline, spanning the three horizons: $1^{\text {st }}$ horizon projects utilise current mature technologies, $2^{\text {nd }}$ horizon projects push technologies into new application areas, and $3^{\text {rd }}$ horizon projects develop new 'blue sky' ideas and often disruptive approaches. 
The first round of investment is the demonstration of feasibility to a required outcome. Engagement of researchers and cross fertilisation of expertise are the first intangible benefits. Technologies develop with steady progress, until they finally reach maturity, and limitations are understood.

The important question is when to invest beyond feasibility. Early adopters gain the first mover advantage and wear the 'teething' risks. There are no easy answers, the industry is littered with gloriously courageous but failed early attempts; Fututech coinciding with the introduction of the cheap but incredible IMB-PC personal computer and other microprocessors, and the lamb hindquarter deboning with the introduction of force feedback in robots, as examples. The challenge comes again with emerging technologies - which one's will fail and which are investment ready? Some investments such as safety technology BladeStop ${ }^{\mathrm{TM}}$ really needed a long-term vision and pushing past doubters.

\section{FIGURE 9}

\section{EMERGING TECHNOLOGIES INCLUDING: EXOSKELETONS, AUGMENTED VISION, AND ARTIFICIAL INTELLIGENCE ALGORITHMS, EACH TO ENHANCE HUMAN PERFORMANCE PHYSICALLY AND WITH INFORMATION}
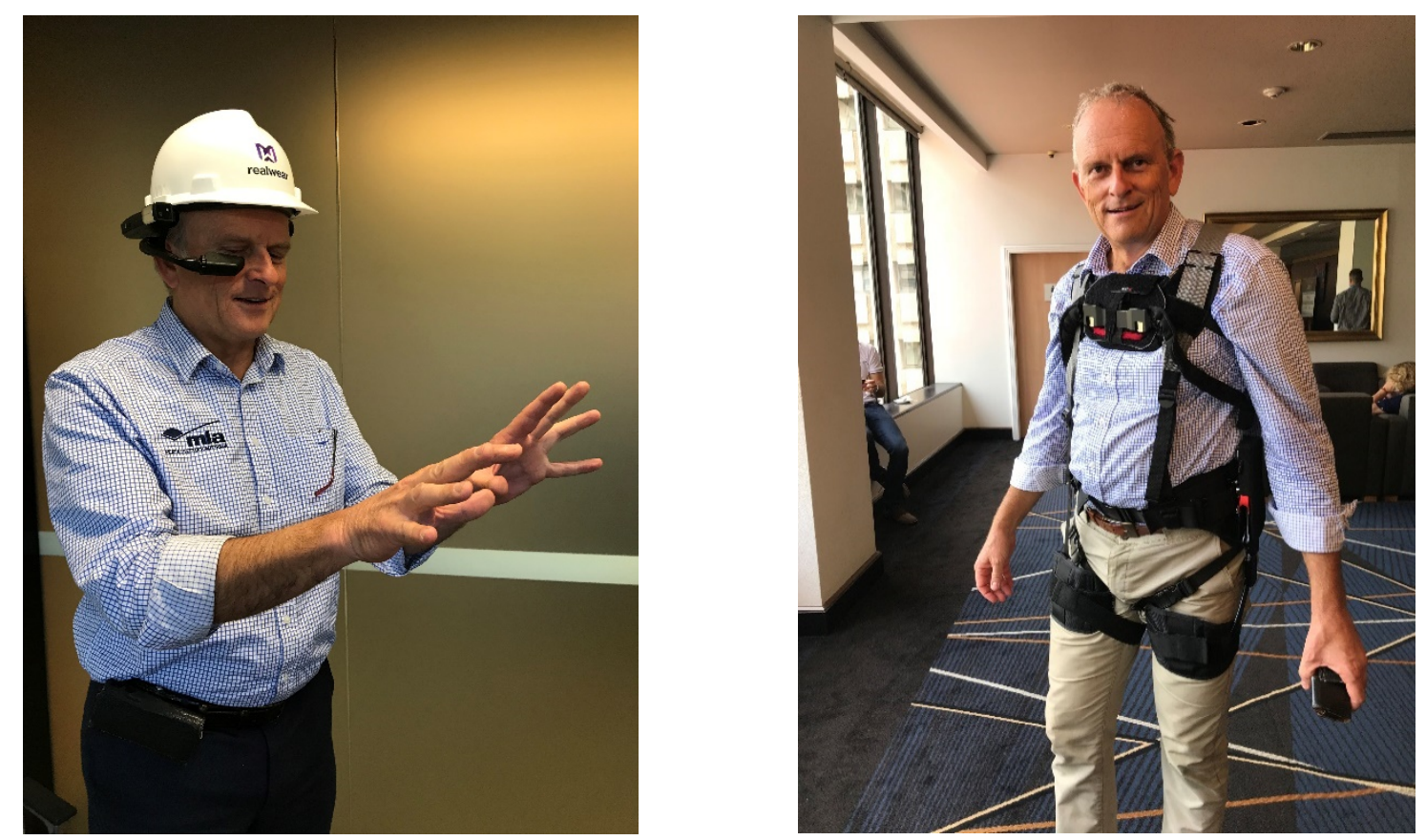

\section{Value Based Trading}

Currently, livestock in the red meat value chain are often traded based on subjective assessments, and often traded on herd or flock averages. This approach leads to often average outcomes, and disadvantages superior performance.

It is anticipated that a move to more precise objective assessment of key value attributes, and trading product with greater transparency and clearer market signalling around value as quantified by customers and consumers, will unlock significant value both to producers and consumers; estimated in hundreds of millions of dollars per annum.

However, the transition from current practices to a new regime is challenging with market forces often penalising early adopters. Ultimately, the industry's best performers will capture the value, and the "Remainers" will need to catch up. 
The Other Unknowns - Commercial Unknown and Business Model, The Human Unknown, and 'When the Penny Drops'

Once all the structural factors are addressed, and technical hurdles achieved, then the delivery of the superior anticipated eating outcome depends upon value chain adoption.

The whole supply chain strives to cooperate and see the collective value of working together, even across competitive boundaries. Hence, seed-stock suppliers need to heed the technical feedback to optimise breeding stock for the purposes required. Livestock producers need to adopt appropriate on-farm animal breeding and husbandry practices based on evidence. Processors need to consider their value propositions and invest in enabling technology. The equation for processors also includes alternative investments, ie; why not just stick to the status quo and buy more livestock to process - the quickest turnover for profit. The equation also includes how the technology provider can support the equipment, the business model: for example is it a simple capital sale with support contract, or is it a per head hardware-as-a-service (HaaS).

And finally, the retail sector can benefit and leverage the improved more consistent product.

Commercial and technical risks can be rationally evaluated, however, there is the human factor around when the 'penny drops' and stakeholders are finally persuaded to adopt. A really compelling value proposition helps.

\section{The Future}

The future is unknowable, but a strategic scenario analysis can provide some insights to assist with the design of a future long-term R\&D program with impact. Future scenarios could include:

1. The industry continues 'as is' - implication is steadily deteriorating global competitiveness, progressive plant closures, processing concentration.

2. The industry invests in technology - accepts but manages and mitigates some risks, maintains global competitiveness, buys technical "options" for participation in continued future innovation.

3. The industry moves off-shore, local slaughter with exported boning and value adding, imported meat products.

To assist with the selection of a future desired scenario, we can consider that; in addition to direct measurable impacts, the Productivity Off-farm technology program featuring robotics also includes many intangible benefits which are significant to longer term community benefit of this technically focused work:

- The widespread adoption of automation in rural centres decentralises high technology into regional areas, and related high value employment opportunities, and community externalities;

- Development activities have increased technology innovation capabilities in Australia, 'thought leadership', and stimulated global investments in Australia;

- Innovation in robotic automation has led to development of more advanced sensing, and in turn led to a whole new program in objective carcase measurement, which has in turn developed solutions and capabilities in biosecurity (ie; Rapiscan aviation CT engagement in Australia with a supporting team approaching 30 technologists). The program has created a valuable technical 'option' for participation in continued future innovation.

- The program investments have supported more rigorous global scanning of important and relevant intellectual property IP, and engaging with leading international technology providers.

For example, intangibles from the Objective measurement program including for instance advanced xray imaging:

- The program developed relationships with the SheepCRC and leading Universities, which in turn led to the formation of the Supply Chain Group which provides a valuable information dissemination network from Paddock to Plate; producers, universities, regional state departments of agriculture, processors, value adders, and retailers. 


\section{CONCLUSION}

The paper aims to discuss the factors that go to delivering the world's best red meat products, and summarising some of the insights and experiences over a long technical career.

The complexity and sophistication leads to a systems based approach, with many levels of competence required. In our modern world, success is based on collaboration, and utilising many clever orthogonal ${ }^{16}$ heads.

There are many gaps yet to be overcome. Technically, the challenges are with advanced imaging and feature segmentation, cost effective robotic seaming and deboning, and process optimisation with artificial intelligence.

Coordination issues include; more effective communication, industry innovation capability, more effective project and program management including risk mitigation, technology readiness evaluation, barriers to adoption, innovations in finance using private equity, and finally the most important - resource sustainability.

\section{ACKNOWLEDGEMENTS}

The MLA supply chain technology program has worked with a number of key contributors, but without being comprehensive, the authors acknowledge the following for their support, insights, and leadership: Dr Christine Pitt, Clyde Campbell, George Waldthausen, Richard Norton, Chris Hopkins, David Doral, and Prof David Pethick.

This paper also acknowledges the contributions of collaborators: Darryl Heidke, Sean Starling, Richard Apps, Andrew Arnold, Associate Professor Graham Gardner, Graham Treffone.

(C) MLA 2019. No part of this publication may be reproduced in any form or by any means without prior written permission of MLA. MLA makes no representations and to the extent permitted by law excludes all warranties in relation to the information contained in this publication. MLA is not liable to you or to any third party for any losses, costs or expenses, including any direct, indirect, incidental, consequential, special or exemplary damages or lost profit, resulting from any use or misuse of the information contained in this publication. Information contained in this publication has been obtained from a variety of third party sources which have not been verified by MLA.

\section{ENDNOTES}

1. Dr Drewe Ferguson and Dr Ian Colditz, CSIROscope article $8^{\text {th }}$ July 2019, 'What does the future hold for livestock production in Australia?'

2. Automated lamb carcase cutting system - Scott Automation \& Robotics SAR and JBS Bordertown plant.

3. State of the Industry Report 2018, MLA and EY, Red Meat Advisory Council.

4. ibid

5. AMPC Strategic risks facing the Australian red meat industry Aug 2016, EY

6. AMPC Cost to operate report Oct 2018, SG Heilbron

7. ibid

8. ibid

9. Australian Industry Skills Committee report on meat production Dec 2018

10. Automated beef rib cutting system - Scott Automation \& Robotics SAR and JBS Dinmore plant.

11. The root cause of innovation system problems: Formative measures and causal configurations, Journal of Business Research, Dr Ian Jenson, 2016

12. MLA Impact Assessment Model developed by George Waldthausen and colleagues.

13. J.E. Hobbs W.A. Kerr K.K. Klein, (1998),"Creating international competitiveness through supply chain management: Danish pork", Supply Chain Management: An International Journal, Vol. 3 Iss 2 pp. 68 - 78

14. Sheep Cooperative Research Centre 2000-2019

15. Scott Automation \& Robotics, Scott Technologies

16. Orthogonal - statistically independent, involving right angles, lateral. 